\title{
Gill histology of Nile tilapia Oreochromis niloticus following chronic and acute exposure to ammonia
}

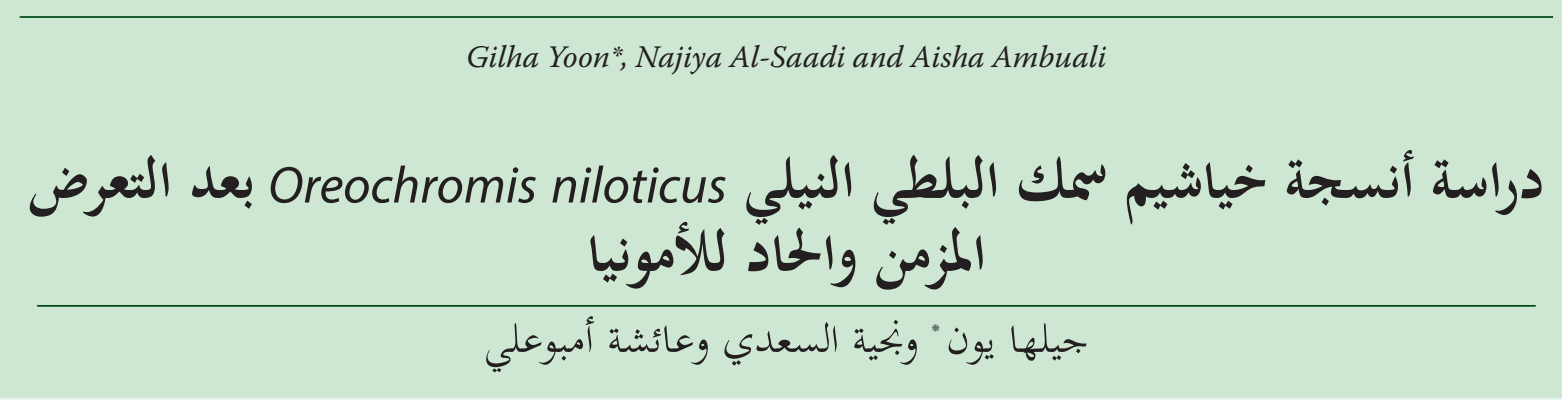

Abstract. Ammonia is a common aquatic pollutant and is toxic to fish. The main nitrogenous compound excreted by fish is also ammonia, which may reach toxic concentrations in high-density fish culture, reducing growth and productivity. In this study, changes in gill structure and mucus cell distribution were examined when juvenile Nile tilapia, Oreochromis niloticus, were exposed to chronic and acute concentrations of ammonia. For chronic exposure, the tilapia were exposed to daily increments in ammonia concentration rising from $0 \mathrm{mg} \mathrm{L}^{-1}$ ammonia on Day 0 to $5 \mathrm{mg} \mathrm{L}^{-1}$ by Day 8; the experiment was terminated on Day 9. There were obvious histopathological changes to the gills over this period including hypertrophy and fusion and of the secondary lamellae. The mucus cell number in gill histology sections were observed to increase until Day 6 then decrease thereafter until the termination of the trial. For the acute exposure, juvenile tilapia were exposed to $5 \mathrm{mg} \mathrm{L}^{-1}$ ammonia for 5 hours. Hourly changes to the gills were monitored, with notable changes to gill filaments and an observed increase in the mucus cell number over the duration of the experiment.

Keyword: Tilapia, gill histology, ammonia, acute, chronic

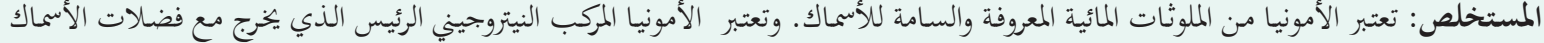

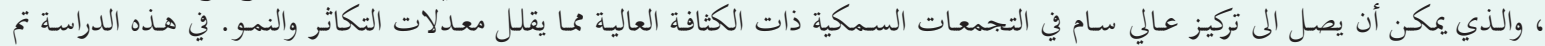

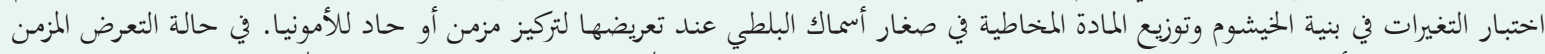

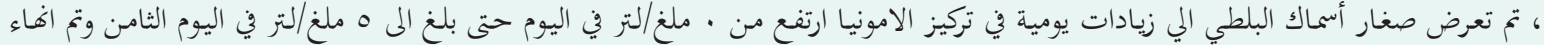

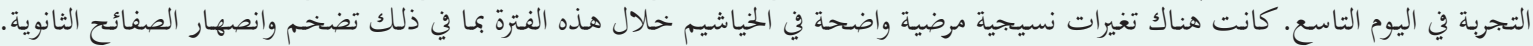

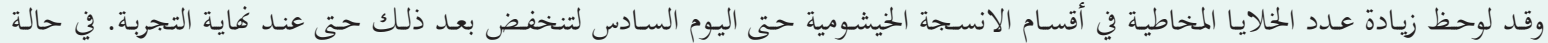

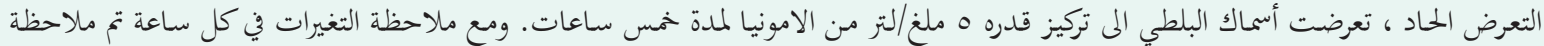

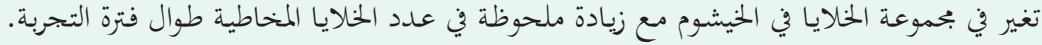

$$
\begin{aligned}
& \text { الكلمات المفتاحية: سمك البلطي ، نسيج الخياشيم ، الامونيا ، التعرض الحاد والمزمن }
\end{aligned}
$$

\section{Introduction}

$\mathrm{T}$ here have been several studies on using protein-rich diets in aquaculture that indicate that, on average, only $25 \%$ of the nitrogen digested by fish is converted to fish biomass (Hargreaves, 1998). The remaining digested nitrogen is mainly excreted by fish as unionized ammonia, as a byproduct of protein metabolism. In finfish aquaculture, without appropriate husbandry interventions, ammonia concentrations can increase to toxic levels, notably in any situation where water is either reused or there is low water exchange. Ammonia is toxic to fish even at very low concentrations and can be a serious problem in aquaculture production (Morrison and Piper, 1988). The gills are important organs for aquatic organisms for gas exchange, ammonia

Sultan Qaboos University, College of Agricultural and Marine Sciences, Department of Marine Science and Fisheries. Box 34, Al-Khod 123. Sultanate of Oman. Gilha Yoon ( $\)$ email: ghyoon@squ.edu.om excretion, osmoregulation and acid-base balance but acute ammonia exposure can alter gill physiology and morphology (Weihrauch et al., 2004). Resultant changes can include epithelial damage, necrosis, and, the collapse of lamellae. The physiological consequences of these changes are likely to affect aquaculture productivity, such as reduced gas exchange, impairment of osmoregulation, reduced growth which if left unaddressed can result in the mortality of stock (Cardoso et al., 1996; Zhao et al., 1997; Rebelo et al., 2000). The nature and degree of toxicity depends on many factors, including the chemical form of ammonia, the $\mathrm{pH}$ and temperature of the water, the length of exposure, and the life stage of the fish being exposed. During acute ammonia poisoning, impairment to the oxygen-carrying capacity of the blood together with other physiological changes can lead to the death of fish (Jensen, 2003). Likewise, the long-term exposure to sub-lethal concentrations of nitrite can also have a considerable impact on fish health and physiological function with subsequent decreases in or suppression of growth, hemoglobin concentration 
and hematocrit values (Voslarova et al., 2008). Nile tilapia, Oreochromis niloticus, is a teleost fish of global economic importance. According to FAO FishStatJ there were 71 nations producing a total of 3,197,330 tonnes of Nile tilapia in 2012. The culture of Nile tilapia within the Sultanate of Oman is still a relatively new activity and as such there has been little research undertaken concerning the effect of ammonia on tilapia reared under environmental conditions typical to the Sultanate of Oman. The aim of the current study, therefore, was to determine changes to gill histopathology when juvenile Nile tilapia were subject to acute and chronic ammonia exposure reared under Omani culture and environmental conditions.

\section{Material and methods}

\section{Chronic exposure to ammonia}

Two static $100 \mathrm{~L}$ glass tanks for the chronic exposure to ammonia and two $100 \mathrm{~L}$ tanks on an independent recirculation system for the control groups of fish were set up. Fifty juvenile tilapia (average total length $13 \mathrm{~cm}$ and average weight $40 \mathrm{~g}$ ) were stocked in each tank and fed feed three times a day (ad libitum to satiation) for 9 days as per the usual management practices of tilapia culture. The concentration of ammonia in each test tank was adjusted on a daily basis so that it increased from $0 \mathrm{mg} \mathrm{L}^{-1}$ on Day 0 to $5 \mathrm{mg} \mathrm{L}^{-1}$ by Day 8 and the end of the trial as follows: Day 0 - $0 \mathrm{mg} \mathrm{L}^{-1}$; Day $1-0.5 \mathrm{mg} \mathrm{L}^{-1}$; Day $2-$ $0.4 \mathrm{mg} \mathrm{L}^{-1}$; Day 3 - $1.5 \mathrm{mg} \mathrm{L}^{-1}$; Day $4-2.7 \mathrm{mg} \mathrm{L}^{-1}$; Day 5 - $1.5 \mathrm{mg} \mathrm{L}^{-1}$; Day 6 - $3 \mathrm{mg} \mathrm{L} \mathrm{L}^{-1}$; Day $7-4 \mathrm{mg} \mathrm{L}^{-1}$; Day 8 and Day $9-5 \mathrm{mg} \mathrm{L}^{-1}$. The water in each of the experimental tanks (i.e. the static tanks with ammonia), were not changed during the 9 day trial but only supplied with aeration. To assess changes to gill histopathology, two fish were randomly selected from each tank each day and prepared for histology, i.e. the gills were dissected out and fixed in $10 \%$ neutral buffered formalin. The total ammonia concentration accumulating in each tank was measured daily using the Hach Kit method.

\section{Acute exposure to ammonia}

For this trial, 10 fish were placed in a $100 \mathrm{~L}$ glass tank containing $5 \mathrm{mg} \mathrm{L}^{-1}$ ammonia for up to 5 hours. Two fish were randomly selected each hour and the gills excised and processed for histology. The concentration of ammonia accumulating in each tank was measured daily using the Hach Kit method. The number and distribution of mucus cells were determined by dewaxing histological sections in xylene and rehydrated them through a graded ethanol series to deionized water. The slides were then stained in alcian blue for 30 mins, rinsed in running tap water for a further 5 mins and then lightly stained lightly with hematoxylin. Thereafter, the sections were rinsed again in running tap water for 5 mins, before transferring them to Scott's water and then a fur- ther 5 min rinse in running tap water. The stained slides were then dehydrated through a graded ethanol series, cleared and mounted. Histopathological changes were examined under a light compound microscope.

\section{Results and discussion}

The gills of fish are a sensitive organ which is easily damaged by a broad spectrum of pollutants, even at low concentrations (Karlsson, 1983). Since the gills perform various vital functions, i.e. respiration, osmoregulation and excretion, and have a large surface area in contact with the external environment, they are particularly sensitive to chemical and physical changes in their aquatic environment (Mallatt, 1985; Mazon et al., 2002; Cerqueira and Fernandes, 2002). In the present study, the ammonia level was gradually increased from $0 \mathrm{mg} \mathrm{L}^{-1}$ on Day 0 to $5 \mathrm{mg} \mathrm{L}^{-1}$ by Day 8 and then maintained at this concentration until the end of the experiment. The histopathological changes to the gills when chronically exposed to ammonia are shown in figure 1 . The tissue sections taken on Day 0 before the addition of ammonia show that there were no deviations from normal gill histology. Thereafter, however, a series of changes were noted, including lamellar deformations as characterised by hyperplasia and fusion of the secondary lamellae, and, hyperemia from day 3 until the end of the experiment. The number of mucus cells was found to increase from Day 1 through Day 6 after which the number began to decline through until the end of the experiment on Day 9 (Fig. 2). Cerqueira and Fernandes (2002) pointed out that as the gills are the principal site for gas exchange, ionic and osmotic regulation and acid-base balance, then histopathological changes to these structures will result in respiratory disturbance and electrolyte imbalance. In a study conducted by Person Le-Ruyet et al.(1998), they were able to demonstrate that ammonia enters the fish 15 min following exposure. The first effects of contaminants usually occur at cellular and subcellular levels, starting from the first hour of contamination. Davison et al.(2014) reported that chronic exposure to nitrate also affects the swimming behaviour as well as the health of fish. In the present study, the important histopathological effects of ammonia on the gills were hyperplasia of the lamella and within the epithelium. Several authors have reported similar alterations to the gills of a range of fish species when exposed to ammonia (Redner and Stickney 1979; Mallatt, 1985; Kucuk, 1999). The study also found that the number of mucus cells changed throughout the duration of the experiment with numbers rising to a peak on Day 6 before declining thereafter. Mucus is considered to be the first line of defense, which can trap and immobilize a range of pathogens before they can contact the epithelial surfaces below (Cone, 2009). Healthy fish secrete and continuously replace their mucus layer as a biological barrier which preventing the stable colonization of potential infectious microorganisms (Salinas et 

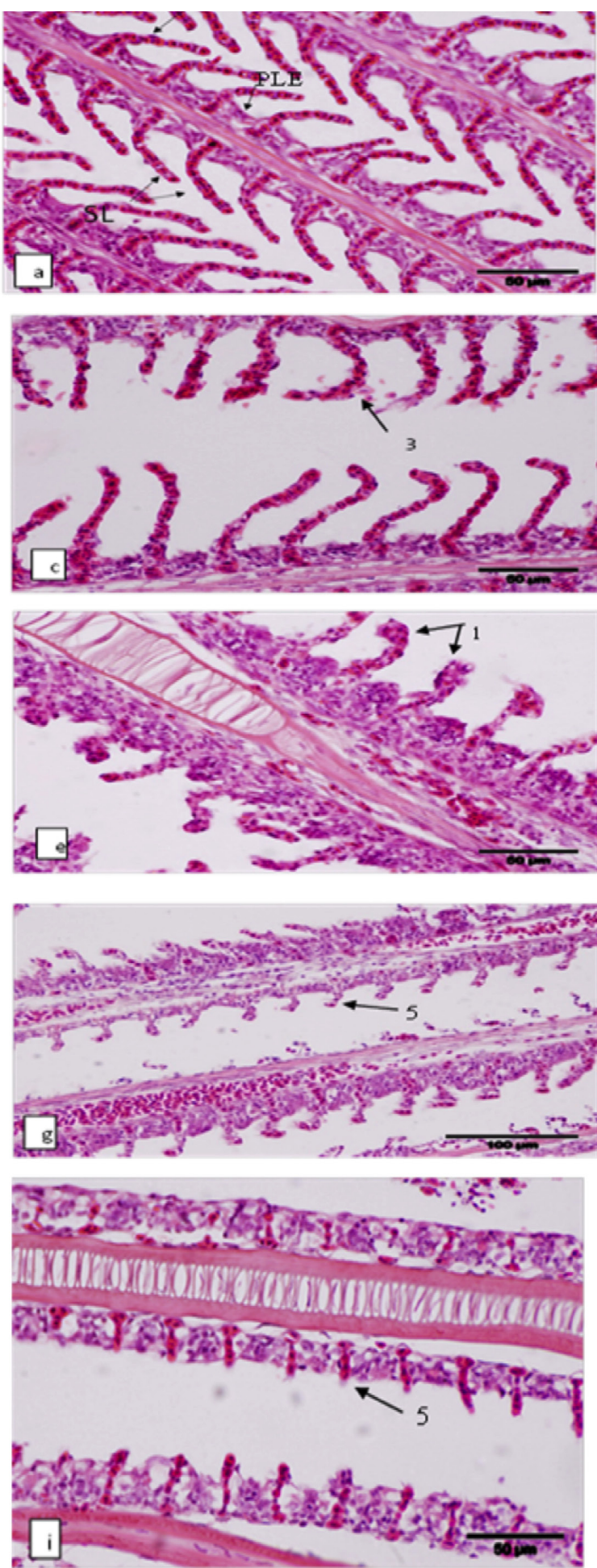
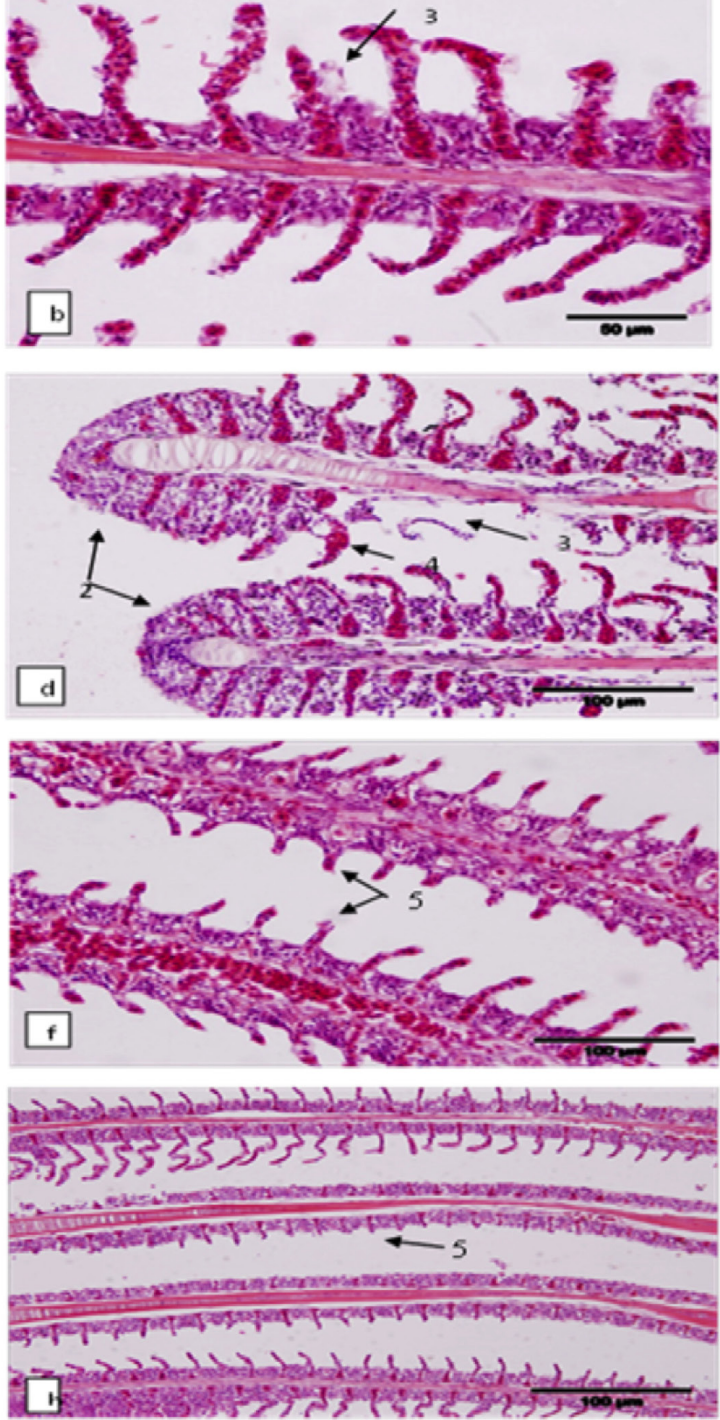

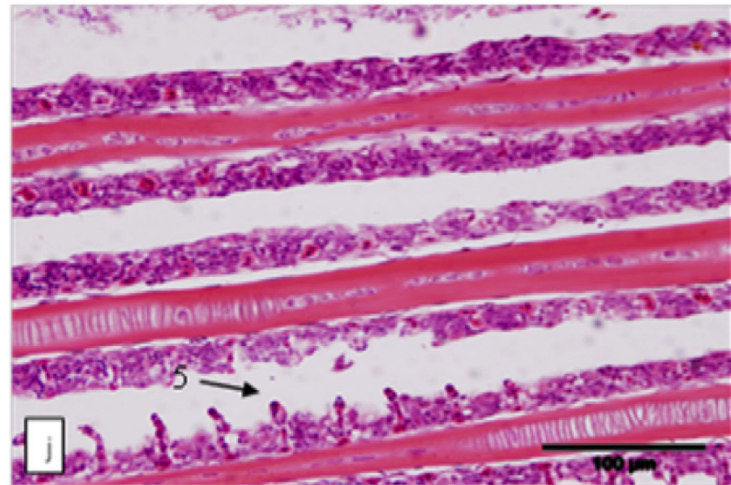

Figure 1. Longitudinal histological sections through the gills of Nile tilapia, Oreochromis niloticus, following chronic exposure to ammonia for 9 days. (a) Condition of the gills at Day 0 prior to the addition of ammonia. Note the structure of the primary lamellar epithelium (PLE) and the secondary lamellae (SL). (b) Day 1: $0.5 \mathrm{mg} \mathrm{L}^{-1}$ of ammonia concentration. (c) Day 2 following exposure to $0.4 \mathrm{mg} \mathrm{L}^{-1}$ ammonia. (d) Day 3 following exposure to $1.5 \mathrm{mg} \mathrm{L}^{-1}$ ammonia. (e) Day 4 and exposure to $2.7 \mathrm{mg} \mathrm{L}^{-1}$ ammonia. (f) Day 5 following exposure to $1.5 \mathrm{mg} \mathrm{L}-1$ ammonia. (g) Day 6 and exposure to $3 \mathrm{mg} \mathrm{L}^{-1} \mathrm{ammonia}$. (h) Day 7 and $4 \mathrm{mg} \mathrm{L}^{-1}$ ammonia. (i) Day 8 following exposure to $5 \mathrm{mg} \mathrm{L}^{-1}$ ammonia. (j) Day 9 and exposure to $5 \mathrm{mg} \mathrm{L}^{-1}$ ammonia. Histopathological changes to the gills are indicated using the following key: (1) hypotrophy; (2) hyperplasia of the secondary lamellae; (3) lifting of the lamellar epithelium; (4) oedema; and, (5) fusion of the secondary lamellae. 

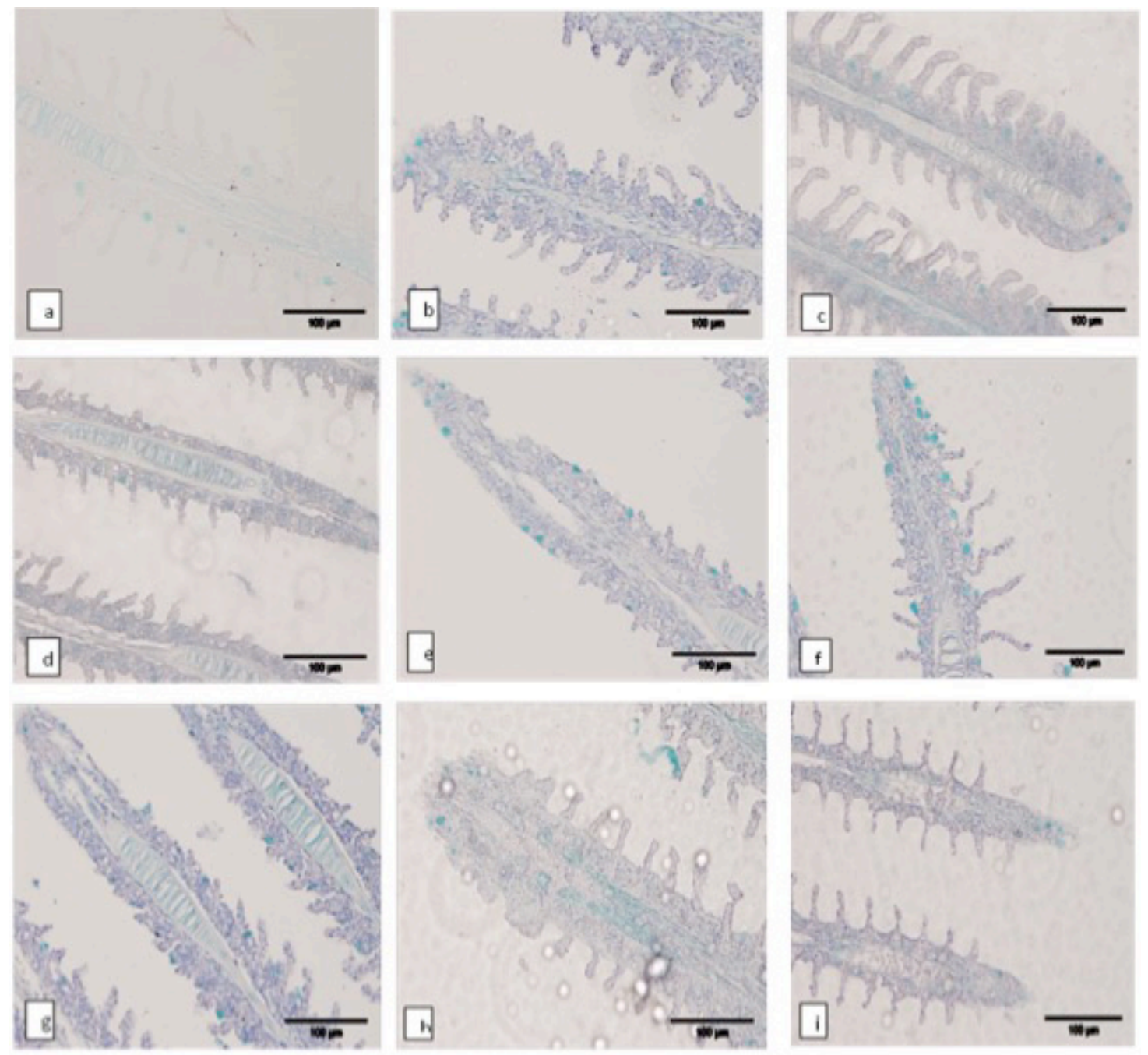

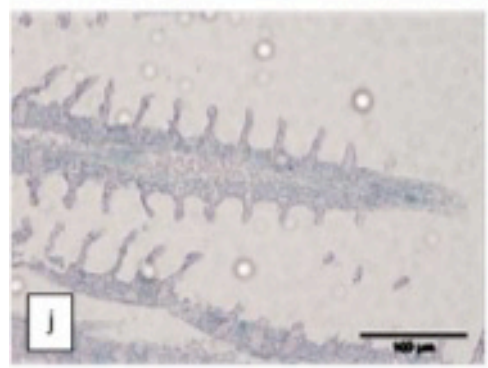

al., 2011).

Although the exposure of juvenile Nile tilapia to a concentration of $5 \mathrm{mg} \mathrm{L}^{-1}$ ammonia for a period of 5 hours resulted in some noticeable deviations to the structure of the gill tissues, i.e., lifting of the lamellar epithelium, these changes were not outside the range of the normal condition of gills (Fig. 3). The number of mucus cells though were seen to increase over the duration of the 5 hour experiment (Fig. 4). Although the concentration of total ammonia was $5 \mathrm{mg} \mathrm{L}^{-1}$, the concentration of harmful un-ionized ammonia was not measured because of a technical problem. It is assumed, therefore, that although a sub-lethal concentration of total ammonia level was used, the concentration of un-ionized ammonia was either low or the period of exposure was too short to induce marked changes. By comparison, Salin and Williot (1991) exposed Siberian sturgeon (Acipencer baeri) to concentrations of ammonia exceeding $60 \mathrm{mg} \mathrm{L}-1$ and found a modification to the epithelium of the secondary lamellae and to the base of the filament which becomes slightly turgescent. Similar results were reported by Mitchell and Cech (1983) from their study with channel catfish (Ictalurus punctatus) and by Cardoso et al.(1996) working with the siluriform catfish Lophiosilurus alexandri. The findings from this trial highlight that even short duration exposure to levels of $5 \mathrm{mg} \mathrm{L}^{-1}$ ammonia can result in measureable changes to the number of mucus cells in the gills. This trial does however highlight a number of limitations to the study, notably the need for the measurement of both the total 

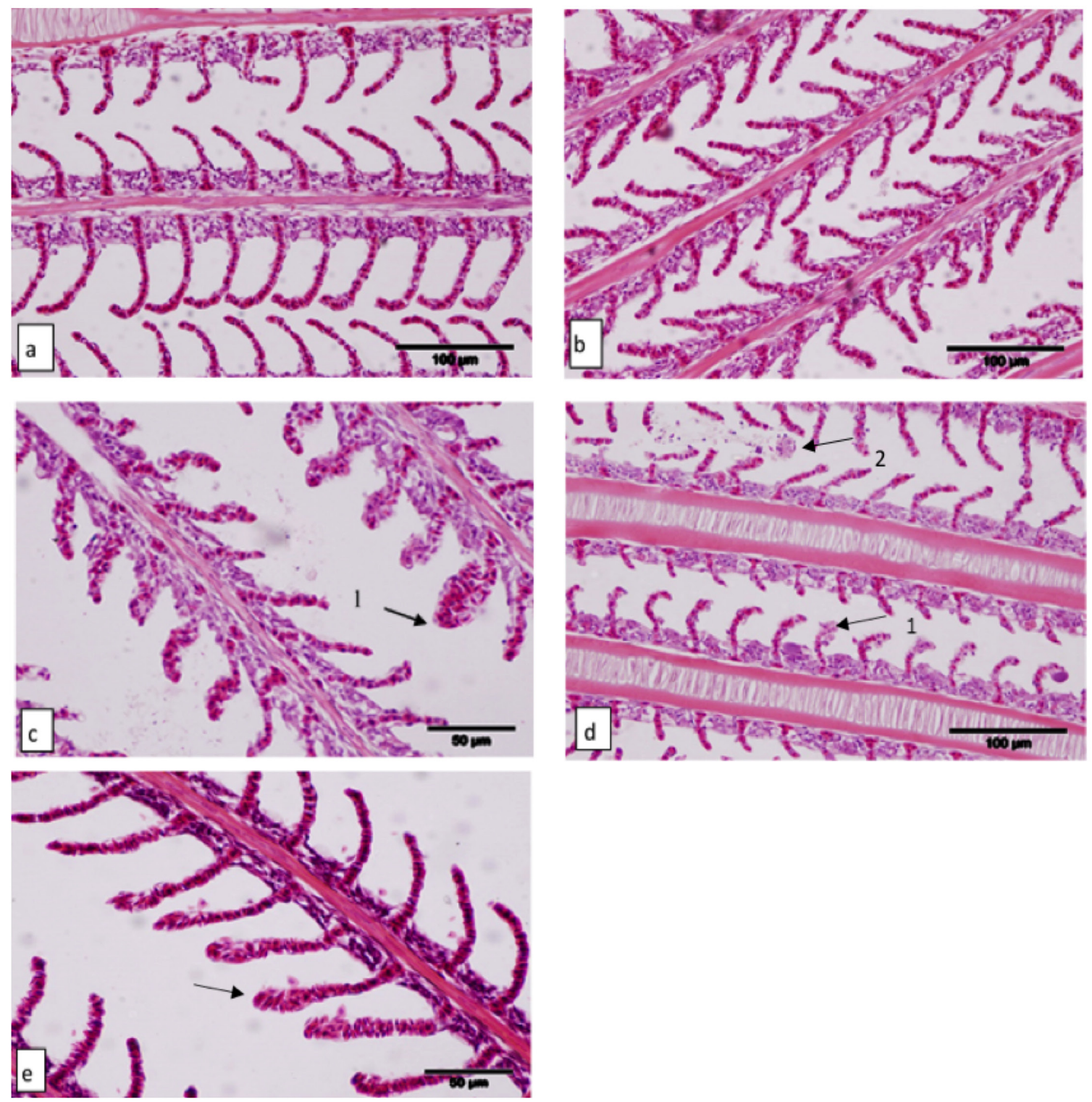

Figure 3. Longitudinal histology sections through the gills of Nile tilapia, Oreochromis niloticus, subjected to an acute exposure of $5 \mathrm{mg} \mathrm{L-1}$ ammonia for a period of 5 hours. (a) to (e) shows the hourly sequential changes to the gills. (a) Gills after exposure to $5 \mathrm{mg} \mathrm{L}-1$ for 1 hour; (b) after 2 hours; (c) after 3 hours; (d) after 4 hours; and, (e) after 5 hours. Histopathological changes to the gills are indicated using the following key: (1) hypotrophy; and, (2) lifting of the lamellar epithelium.

and unionized ammonia content in all future trials.

\section{Conclusions}

In the trial where juvenile Nile tilapia were chronically exposed to ammonia, there were no detectable alterations to the gill tissues until Day 3. After Day 3, at which point the ammonia concentration had been raised to $1.5 \mathrm{mg} \mathrm{L}^{-1}$ ammonia, lamellar deformations characterised by hyperplasia and fusion of the secondary lamellae with hyperemia were seen noted. During this trial, a gradual increase in the number of mucus cells was noted up until Day 6, after which the number declined to Day 9 when the trial was terminated. The most important observed histopathological deviations were hyperplasia of the gill lamellae and hyperemia of the epithelium. In the 5 hour, $5 \mathrm{mg} \mathrm{L}^{-1}$ ammonia acute exposure trial, some lifting of the lamellar epithelium was noted but both were minor and can be regarded as being within the normal condition. The number of mucus cells in this trial were also seen to increase over the 5 hour period of exposure. Changes to the gill tissues were more severe in the chronic exposure trial with hyperplasia of the secondary lamellae, lifting of the lamellar epithelium, oedema and fusion of the secondary lamella being seen as consequential changes. The increase in mucus cell number and, therefore, mucus production serves 

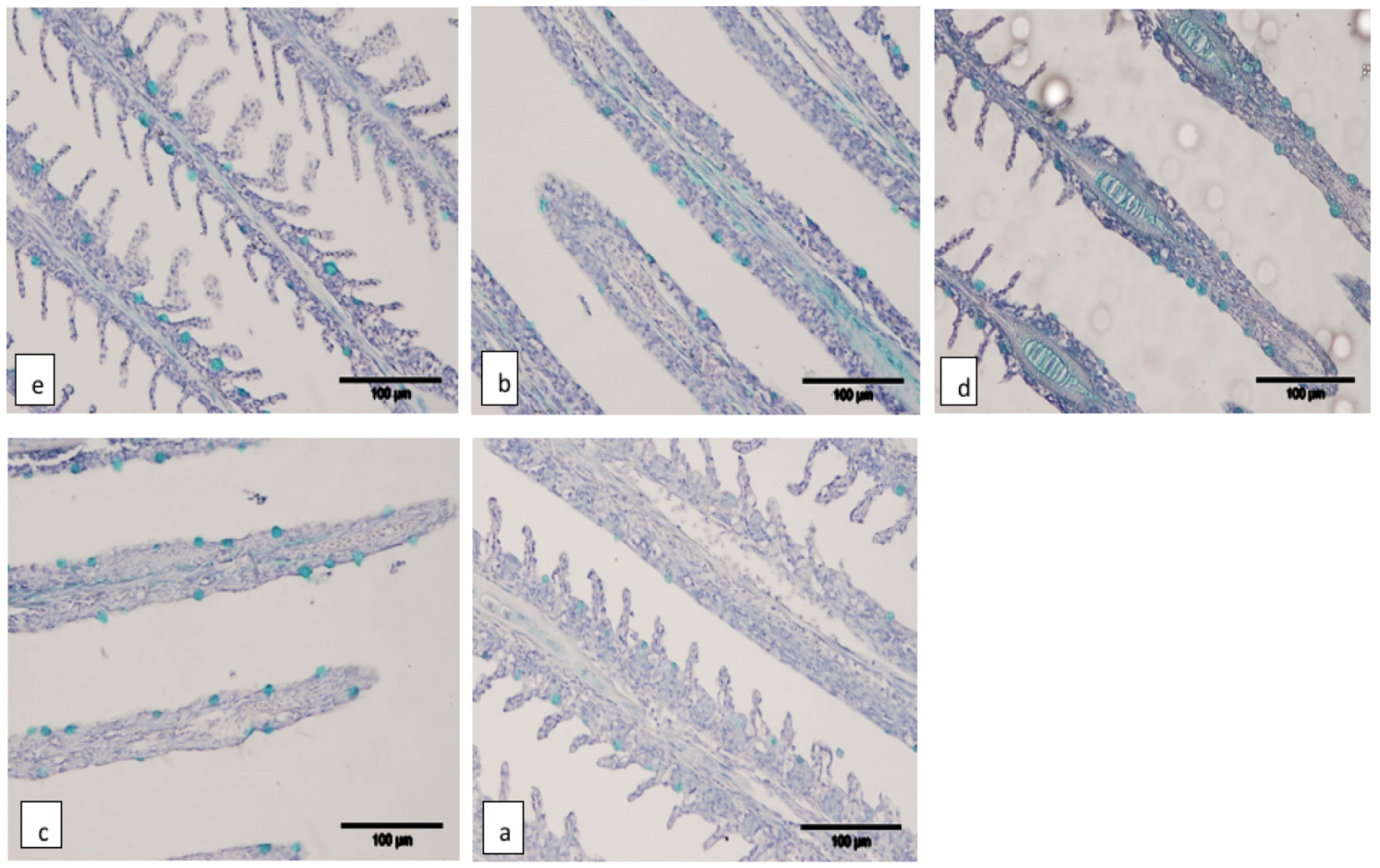

Figure 4. Changes in the distribution of mucus cells in the gills of Nile tilapia, Oreochromis niloticus, when acutely exposed to $5 \mathrm{mg} \mathrm{L}^{-1}$ ammonia for a period of 5 hours.

to protect the gills, as part of the fish's frontline defense mechanism, from the effects of rising ammonia levels.

\section{Acknowledgements}

This study was supported through an Internal Grant (project code: IG/AGR/FISH/13/02) from Sultan Qaboos University, Oman, Sultanate of Oman

\section{References}

Cardoso, E.L., H. Chiarini-Garcia, R.M.A. Ferreira, and C.R. Poli. 1996. Morphological changes in the gills of Lophiosilurus alexandri exposed to un-ionized ammonia. Journal of Fish Biology 49: 775-787.

Cerqueira, C.C.C., and M.N. Fernandes. 2002. Gill tissue recovery after copper exposure and blood parameter responses in the tropical fish Prochilodus scrofa. Ecotoxicology and Environmental Safety 52: 83-91.

Cone, R.A. 2009. Barrier properties of mucus. Advanced Drug Delivery Reviews 61: 75-85.

Davison, J., C. Good, C. Welsh, and S.T. Summerfelt. 2014. Comparing the effects of high vs. low nitrate on the health, performance, and welfare of juvenile rainbow trout Oncorhynchus mykiss within water recirculating aquaculture systems. Aquaculture Engineering 59: 30-40.

Hargreaves, J.A. 1998. Nitrogen biochemistry of aquaculture ponds. Aquaculture 166: 181-212.
Jensen, F.B. 2003. Nitrite disrupts multiple physiological functions in aquatic animals. Comparative Biochemistry and Physiology 135: 9-24.

Karlsson, L. 1983. Gill morphology in the zebrafish, Brachydanio rerio (Hamilton-Buchanan). Journal of Fish Biology 23: 511-524.

Kirk, R.S., and J.W. Lewis. 1993. An evaluation of pollutant induced changes in the gills of rainbow trout using scanning electron microscopy. Environmental Technology 14: 577-585.

Mallatt, J. 1985. Fish gill structural changes induced by toxicants and other irritants: a statistical review. Canadian Journal of Fisheries and Aquatic Sciences 42: 630-648.

Mazon A.F., E.A.S. Monteiro, G.H.D. Pinheiro, and M.N. Fernandes. 2002. Hematological and physiological changes induced by short-term exposure to copper in the freshwater fish, Prochilodus scrofa. Brazilian Journal of Biology 62: 621-631.

Mitchell, S.J., and J.J. Cech. 1983. Ammonia caused gill damage in channel catfish (Ictalurus punctatus): confounding effects of residual chlorine. Canadian Journal of Fisheries and Aquatic Sciences 40: 242-247.

Morrison, J.K., and R.G. Piper. 1988. The effect of reused water on Atlantic salmon. Progressive Fish Culturist 50: 110-112.

Person Le- Ruyet, J.P., G. Boeuf, J.Z. Infante, S. Helga- 
son, and A. Roux. 1998. Short-term physiological changes in turbot and seabream juveniles exposed to exogenous ammonia. Comparative Biochemistry and Physiology 119: 511-518.

Pinto, W., C. Aragao, F. Soares, M.T. Dinis, and L.E.C. Conceicao. 2007. Growth, stress response and free amino acid levels in Senegalese sole (Solea senegalensis Kaup 1858) chronically exposed to exogenous ammonia. Aquaculture Research 38: 1198-1204.

Rebelo, M.F., E.M., Rodriguez, E.A. Santos, and M. Ansaldo. 2000. Histopathological changes in gills of the estuarine crab Chasmagnathus granulata (Crustacea-Decapoda) following acute exposure to ammonia. Comparative Biochemistry and Physiology 125: 157-164.

Redner, B.D., and R.R. Stickney. 1979. Acclimation to ammonia by Tilapia aurea. Transactions of the American Fisheries Society 108: 383-388.
Salin, D., and P. Williot, 1991. Acute toxicity of ammonia to Siberian sturgeon (Acipencer baeri). In: Williot, P. (Ed.). Acipenser. Cemagref Publication. pp. 153-167.

Salinas, I., Y.-A. Zhang, and O. Sunyer. 2011. Mucosal immunoglobulins and B cells of the teleost fish. Developmental and Comparative Immunology 35: 1346-1365.

Weihrauch, D., M.P. Wilkie, and P.J. Walsh, 2009. Ammonia and urea transporters in gills of fish and aquatic crustaceans. Journal of Experimental Biology 212: 1716-1730.

Zhao, J.-H., T.J. Lam, and J.Y. Guo. 1997. Acute toxicity of ammonia to the early stage-larvae and juveniles of Eriocheir sinensis H. Milne-Edwards, 1853 (Decapoda: Grapsidae) reared in the laboratory. Aquaculture Research 28: 517-525. 